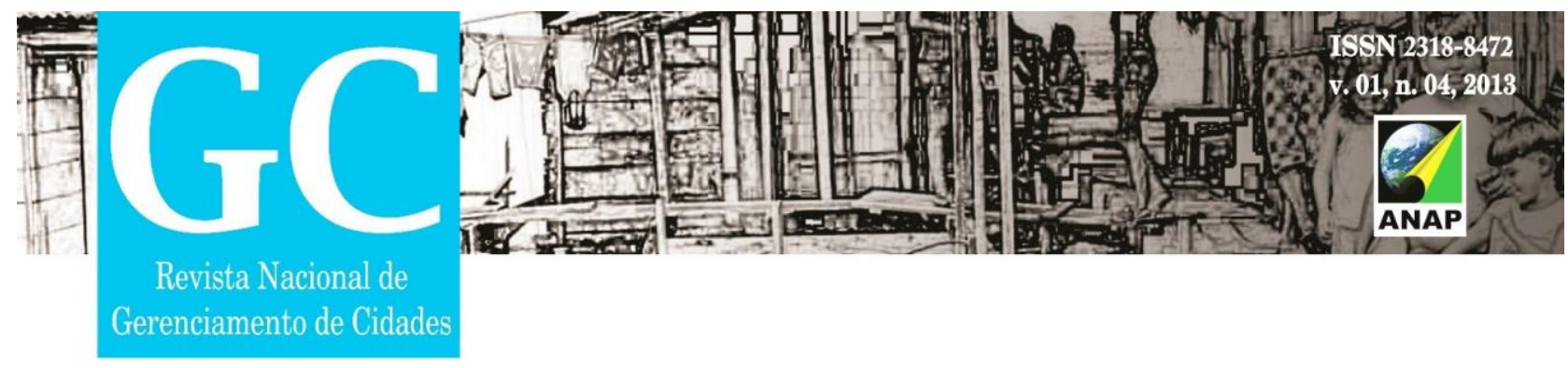

Titulo do Trabalho

\title{
COMPREENSÃO SOBRE A EVOLUÇÃO URBANA DAS CIDADES PORTUÁRIAS DE SANTANA NO AMAPÁ E CAIENA NA GUIANA FRANCESA
}

Nome do Autor (a) Principal

\section{Tárcio Renato Silva Martins}

Nome do Orientador

José Alberto Tostes

Instituição ou Empresa

Universidade Federal do Amapá - UNIFAP

E-mail de contato

tarciorenato@gmail.com

Palavras-chave

Planejamento Urbano, Sustentabilidade Urbana e desenvolvimento local.

\section{INTRODUÇÃO}

As cidades portuárias tem configuração fortemente influenciada pelas atividades econômicas formais e informais. Neste contexto, a cidade de Santana (AP) tem características peculiares, e com predominância de atividades de serviços e comércio ao longo de sua orla. $\mathrm{Na}$ cidade de Caiena, a orla portuária tem características mais artificializadas, funciona basicamente como um terminal de carga e descarga.

As cidades de Santana (AP) e Caiena (GF) possuem distintas organizações políticas, por serem de blocos econômicos distintos, embora, ambas estejam localizadas na América do Sul. Santana é uma cidade portuária com os problemas comuns entre as cidades brasileiras, apesar de vários entraves, possui configuração mais flexível, enquanto, no outro bloco, Caiena na Guiana Francesa, possui características econômicas 


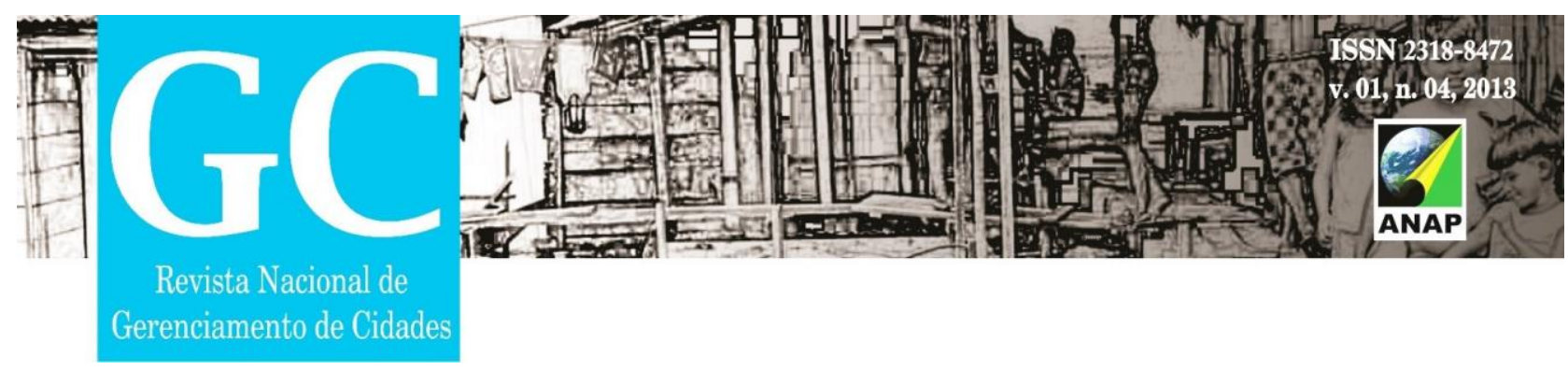

e culturais européias, destacando-se o rigor das regras estabelecidas pela União Européia.

Este trabalho desta norteado pela seguinte indagação: Quais fatores norteiam a evolução urbana das cidades portuárias de Santana no Amapá e Caiena na Guiana Francesa? As estratégias de ocupação e desenvolvimento da década de 90 no Brasil, as propostas de integração como a ponte binacional.

\section{OBJETIVO GERAL}

- Analisar a evolução urbana das cidades portuárias de Santana no Amapá e Caiena na Guiana Francesa.

\section{OBJETIVO ESPECÍFICO}

- Levantar dados sobre a configuração das cidades Santana e Caiena; quantificar os indicadores das cidades amapaenses e guianenses, comparar os dados verificando as possíveis inter-relações na região do platô das guianas.

\section{METODOLOGIA}

Os estudos metodológicos estão pautados na análise dos planos diretores; elaborados para as cidades de Santana e Caiena; na visão institucional para Caiena, nas pesquisas levantadas em diversos setores e acervos históricos e no estudo de material cartográfico produzido por setores de planejamento urbano de ambas as cidades. 


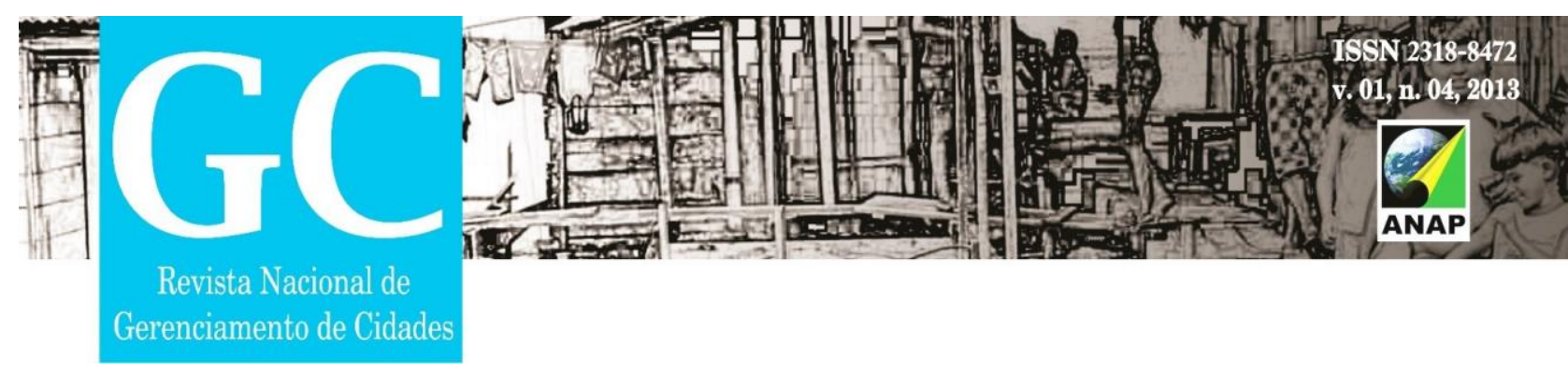

\section{RESULTADOS}

- Produção de cartografias sobre a infraestrutura de planejamento urbano das cidades de Santana e Caiena.

- A compreensão do processo de formação histórica e urbana das cidades de Santana e de Caiena (GF);

- Demonstração dos vínculos de integração das áreas portuárias das cidades de Santana e Caiena para o desenvolvimento da economia local.

\section{CONSIDERAÇÕES FINAIS}

Em Santana é muito mais visível que a zona portuária tenha uma dinâmica mais intensa do ocorre em Caiena, onde a orla portuária tem características mais secundárias em relação à estrutura da cidade. Neste processo de analise, fica a evidenciado as distintas atribuições evolutivas de conformidade com a evolução urbana das cidades de Santana (AP) que possui características urbanas baseadas em um planejamento com alguma tentativa de inserção social, na cidade de Caiena (GF), há uma concepção mais tecnocrata baseada no pragmatismo das proposições da União européia.

Os dados obtidos e as cartografias elaboradas possibilitaram ao longo do processo, visão ampla sobre as principais relevâncias de evolução urbana destas cidades, além de ressaltar um conjunto de informações que auxilia a compreender os diferentes estágios socioeconômicos de tais cidades. 


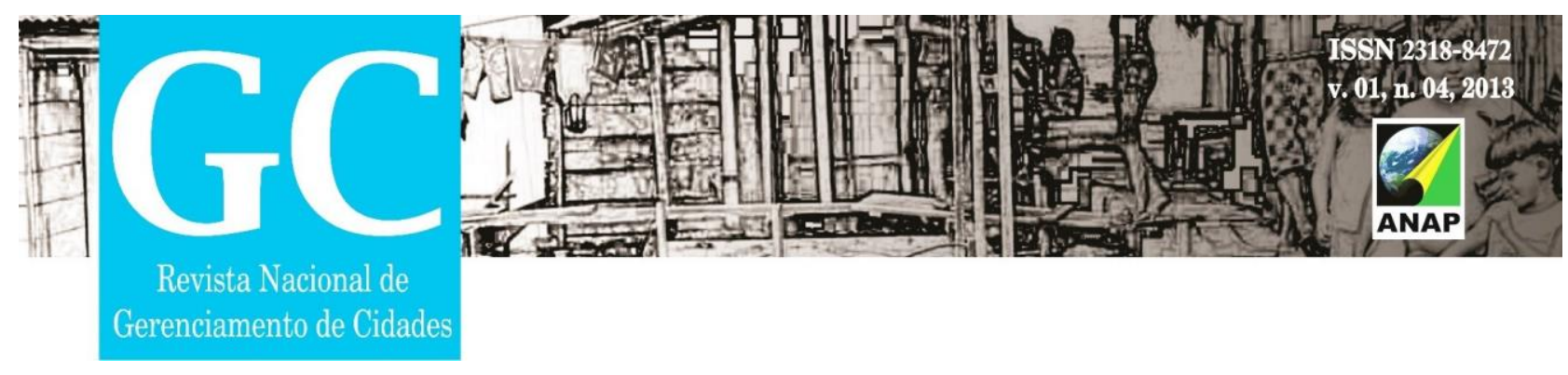

\section{REFERENCIAS}

AMADO, M. Planejamento Urbano Sustentável. Caleidoscópio. Edição e Artes Gráficas, Casal de Cambra, 2005.

CARLOS A.F.A. O espaço urbano: novos escritos sobre a cidade. Eletrônica - LABUR. São Paulo,2007.

CASTRO, M. L. E PORTO J.L.R. Ponte Brasil-Guiana francesa: os paradoxos da integração em um contexto multi-escalar. Olkos: revista de economia heterodoxa, ํㅜ․ 2007.

LIMA, July F. Alcolumbre. Cidades de Santana (AP) e Caiena (GF): Um estudo comparativo sobre a concepção de planejamento urbano - 2000-2011. 2013, Tese de Conclusão de Curso (Bacharelado em Arquitetura e Urbanismo) - UNIFAP, Santana.

MARICATO, Ermínia. Brasil, cidades: alternativas para a crise urbana. Petrópolis: Editora Vozes, 2000.

PORTO J.L.R E SILVA G.V. De periferia a espaço estratégico: a construção da condição fronteiriça amapaense. $7^{\circ}$ Workshop - XXXVI Reunión de estúdios regionales - AECR, 2010.

SANTOS, Emmanuel. Dinâmica da articulação fronteiriça amazônica no platô das guianas através do desenvolvimento da configuração territorial e urbana do estado do Amapá/Brasil. UNESP, 2010.

SANTOS, Milton. A urbanização Brasileira, São Paulo: Hucitec, 1993.

SOUZA M.L.- ABC do Desenvolvimento Urbano. Rio de Janeiro: $2^{\underline{a}}$ Edição. Bertrand, 2005.

TOSTES, José Alberto. Gestão e planejamento do atraso. Versão editada em http://josealbertostes.blogspot.com, acesso em 20/07/2012.

UGEDA JR, José Carlos. Urbanização brasileira, planejamento urbano e planejamento da paisagem. Faculdade de Ciências e Tecnologia (FCT) Universidade Estadual Paulista. 2008. 